\title{
Atypical Presentation of Classical Bartter Syndrome as a Case of Chronic Diarrhea and Failure to Thrive*
}

\author{
Anil Kumar Mohanty, Deepti Damayanty Pradhan, Bijay Kumar Meher, Pradeep Sivraj \\ Department of Paediatrics, Sardar Vallavbhai Patel Post Graduate Institute of Paediatrics (SCB Medical College), Cuttack, India \\ Email: bkmeher187@yahoo.co.in
}

Received November 20, 2013; revised December 10, 2013; accepted December 20, 2013

Copyright (C) 2013 Anil Kumar Mohanty et al. This is an open access article distributed under the Creative Commons Attribution License, which permits unrestricted use, distribution, and reproduction in any medium, provided the original work is properly cited.

\begin{abstract}
The classical Bartter syndrome is an uncommon tubular disorder of autosomal recessive inheritance, characterized by early childhood onset of polyuria, polydipsia, vomiting, dehydration, constipation and salt craving habit. The long-term outlook for patients with Bartter syndrome is not certain. If not properly treated, it may lead to failure to thrive and growth retardation. We herein report a case of 18-month-old girl child who presented chronic diarrhea and failure to thrive and then was diagnosed as a case of classical Bartter syndrome. She was successfully treated with potassium supplementation and ibuprofen therapy.
\end{abstract}

Keywords: Bartter Syndrome; Chronic Diarrhea; Ibuprofen Therapy

\section{Introduction}

Bartter Syndrome first described in 1960 but, over the years several phenotypic and genotypic variants of original description of Bartter syndrome have been identified [1,2]. The classical Bartter syndrome (BS) is characterized by early childhood onset with polyuria, polydipsia, vomiting, constipation, salt craving, severe dehydration, failure to thrive and growth retardation [3]. It is an uncommon tubular disorder, characterized by metabolic alkalosis, hyponatremia, hypokalemia, hypochloremia, with hyper-reninemia and hyperaldosteronemia, and normal or low blood pressure associated with increased loss of sodium, potassium, calcium and chloride in the urine [4].

\section{Case Report}

An 18-month-old female child born out of non-consanguineous marriage presented with history of vomiting, poor feeding, on and off low grade fever, loose motion and weight loss for 3 months. Vomiting was projectile, non-bilious, and $6-8$ times per day. The loose motion was watery sometimes mucoid $6-8$ times daily and was continuing for last 3 months and was hospitalized in local hospital twice for dehydration but loose motion did not relieved by treatment. There was no history of decrease

*Funding: none; Conflicting interest: none. in urination. This child was $4^{\text {th }}$ order, term normal vaginal delivery, birth weight being 2800 gm with uneventful perinatal period. Baby was on exclusive breast fed up to 6 months of age and thereafter was on home based cereal diet. Developmental milestones were normal till about 15 months of age then unable to stand and walk and started crawling. In the sibling history, $1^{\text {st }}$ male child died at 4 months and $2^{\text {nd }}$ female child died at 6 months due to unknown reasons, $3^{\text {rd }}$ female child was 5 years old and doing well.

On examination, at admission, the patient was cachectic, afebrile, lethargic, severely dehydrated, having tachycardia, tachypnea, hypotension, weight $5.5 \mathrm{~kg}$, (previous documented weight at 6 months was $6.5 \mathrm{~kg}$ and at 1 year was $8 \mathrm{~kg}$.) without stunting, head circumference $45 \mathrm{~cm}$, MAC-10 $\mathrm{cm}$ with US/LS ratio of 1.4. (Figure 1) She was pale, without having lymphadenopathy, jaundice, cyanosis, clubbing or edema with systemic examinations being normal. Clinical diagnosis at admission was chronic diarrhea with failure to thrive.

On investigation, microcytic hypochromic anemia with normal erythrocyte sedimentation rate (ESR) and normoglycemia, without any features of infection (total leucocyte counts, C-reactive protein, urine microscopy including culture were normal). Stool examination revealed no red blood cells, pus cell, parasites, fat globules and normal level of reducing sugars. Serum albumin was $3 \mathrm{gm} / \mathrm{dL}$. Renal function test revealed normal serum- 


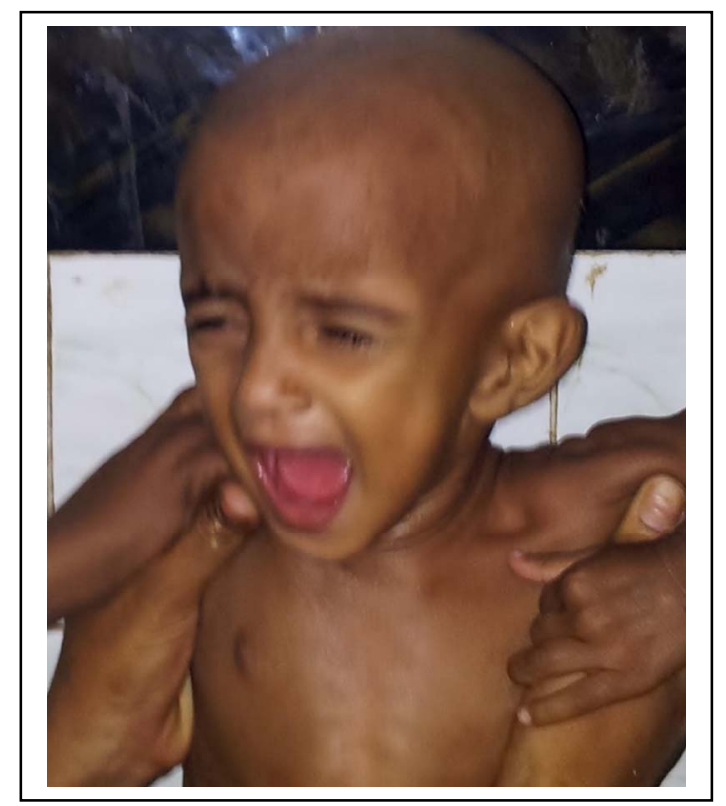

Figure 1. 18-month-old child with failure to thrive and note the irritability of the child.

urea, creatinine with hyponatremia $(118 \mathrm{mEq} / \mathrm{L})$, hypokalemia $(2.9 \mathrm{mEq} / \mathrm{L})$, hypochloremia $(85 \mathrm{mEq} / \mathrm{L})$. ABG revealed metabolic alkalosis with $\mathrm{pH}$ 7.771; bicarbonate $26 \mathrm{mEq} / \mathrm{L}$. Spot urinary sodium was $184 \mathrm{mEq} / \mathrm{L}$, potassium $14 \mathrm{mEq} / \mathrm{L}$, calcium $12.6 \mathrm{mEq} / \mathrm{L}$, chloride- 112 $\mathrm{mEq} / \mathrm{L}$. Serum tissue transglutaminase level was normal. Ultrasonogram of abdomen was normal. Bartter syndrome was suspected in the view of metabolic alkalosis with high urinary excretion of chloride, hyponatremia, hypokalemia and hypochloremia and then blood sample was sent for serum renin and aldosterone.

The child was initially managed with intravenous fluids followed by oral rehydration solution (ORS) and F-75 diet. Serum aldosterone and serum renin were found to be raised i.e. $551.57 \mathrm{pg} / \mathrm{ml}$ (normal $25-315 \mathrm{pg} / \mathrm{ml}$ ) and $87.6 \mathrm{uIU} / \mathrm{ml}$ (normal upright-4.4 to-46.1 uIU/ml, supine-2.8- to $39.9 \mathrm{uIU} / \mathrm{ml}$ ) respectively. Later on child was started on F-100 diet, potassium supplementation and Ibuprofen therapy $(30 \mathrm{mg} / \mathrm{kg} /$ day $)$. With this treatment, child improved symptomatically (vomiting and stool frequency was reduced, her appetite improved) and she gained 600 gram during the hospital stay. Repeat Serum electrolytes showed normal sodium $(137 \mathrm{mEq} / \mathrm{L})$, low normal potassium $(3.1 \mathrm{mEq} / \mathrm{L})$, and low normal Calcium $(0.9 \mathrm{mEq} / \mathrm{L})$.

During follow up after 4 month there was no diarrhea, weight was increased to $7.7 \mathrm{~kg}$, height $75 \mathrm{~cm}$ and serum electrolyte was normal except for low normal potassium level (sodium $139 \mathrm{mEq} / \mathrm{L}$, potassium $3.36 \mathrm{mEq} / \mathrm{L}$, Calcium $1.0 \mathrm{mEq} / \mathrm{L})$. At 10 months follow up, the weight was $9.5 \mathrm{~kg}$, height $82 \mathrm{~cm}$ (Figure 2) and serum electrolytes were normal.

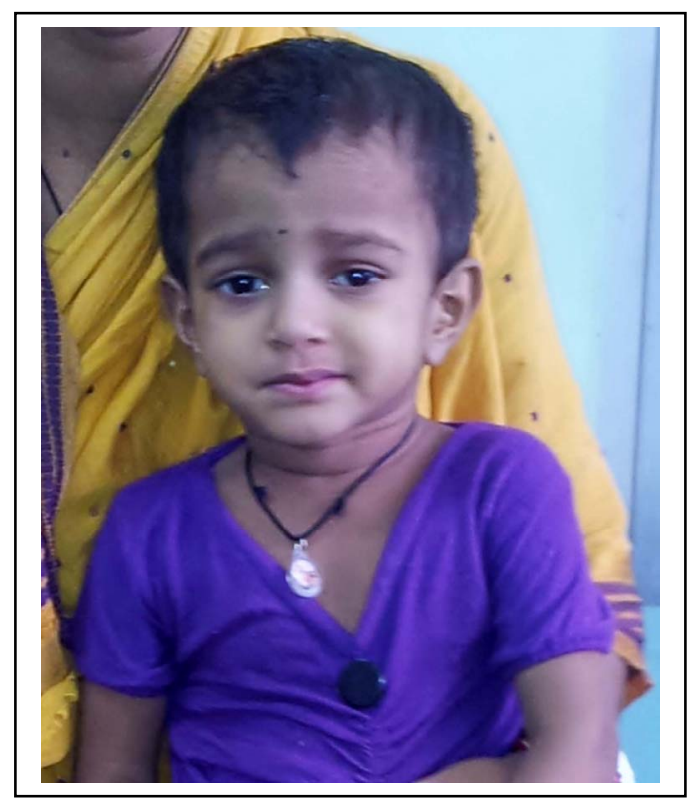

Figure 2. Same child during follow up after 10 months of treatment.

\section{Discussion}

Bartter syndrome is rare autosomal recessive renal tubular disorders characterized by hypokalemia, hypochloremia, metabolic alkalosis, and hyperreninemia with normal blood pressure. The underlying renal abnormality results in excessive urinary losses of sodium, chloride, and potassium. The occurrence varies from country to country. Incidence of our country is not known. In Costa Rica, the frequency of neonatal Bartter syndrome is approximately 1.2 cases per 100,000 live births but is higher if all preterm births are considered. Bartter syndrome has traditionally been classified into 3 main clinical variants: neonatal (or antenatal) Bartter syndrome, classical Bartter syndrome, and Gitelman syndrome. Abnormalities of classical Bartter syndrome are all suggestive of a defect related to $\mathrm{Cl}^{-}$transport in the medullary thick ascending loop of Henle and distal convoluted tubule (DCT). Failure to reabsorb chloride results in a failure to reabsorb sodium and leads to excessive sodium and chloride (salt) delivery to the distal tubules, leading to excessive salt and water loss from the body and activation of renin-angiotensin aldosterone system (RAAS).

Our case presented at 18 months of age with severe dehydration and failure to thrive. We initially treated as a case of diarrhea; child improved symptomatically and again went in for severe dehydration. But the urine output was not impaired even in severe dehydration. Blood and urine investigations revealed increased loss of sodium, potassium, chloride and calcium. After then, serum renin and aldosterone was found high and treated in line of Bartter syndrome, child improved with our treatment. K. Sampatkumar et al. [5] in an Indian series of child- 
hood Bartter syndrome had found the mean age of presentation at $6.5 \pm 4.9$ months with features of vomiting, FTT, polyuria, dehydration, some with fever, irritability, respiratory difficulty, alkalosis, hypokalemia, hypochloremia, hyponatremia. However in their series no diarrhea was reported.

In another case report by P Samayam et al. [6] a 5year old child had presented with history of recurrent vomiting, generalized weakness, FTT, dehydration, pallor which was diagnosed to be Bartter syndrome, and treated with Potassium supplements \& ibuprofen along with appropriate dietary advice \& improved on follow up. However no diarrhea was associated.

P Saravan kumar et al. [7] reported a case of neonatal Bartter syndrome which presented at age of 2 months 10 days with diarrhea, vomiting, abdominal distention and FTT since 20 days of life. But diarrhea was controlled with treatment and hypokalemia persisted, so Bartter syndrome was suspected and diagnosed by investigation. However in our case the diarrhea persisted and did not respond to treatment. But diarrhea stopped with treatment of Bartter syndrome in form of potassium supplements and ibuprofen therapy.

\section{Conclusions}

Bartter syndrome should be suspected in any case of Vomiting and FTT. Also some cases of diarrhea and FTT with normal urination should be strongly suspected.

\section{What is already known?}

FTT and persistent vomiting cases should be investigated for Bartter syndrome.

What the study adds?

FTT and chronic diarrhea cases should also be investigated for BS.

Limitation of the study: We could not do genetic analysis of the child. More cases should be studied in fu- ture.

\section{Contributors}

AK overall designed the study. DP \& BM case study and follow up, BM \& PS preparing manuscript.

\section{REFERENCES}

[1] F. C. Bartter, P. Pronove, J. R. Gill and R. C. MacCardle (with tech. assistance of Diller E), "Hyperplasia of the Juxtraglomerular Complex with Hyperaldosteronism and Hypokalemic Alkalosis. A New Syndrome," The American Journal of Medicine, Vol. 33, No. 6, 1962, pp. 811828. http://dx.doi.org/10.1016/0002-9343(62)90214-0

[2] W. Proesmans, "Threading through the Mizmaze of Bartter Syndrom," Pediatric Nephrology, Vol. 21, No. 7, 2006, pp. 896-902.

http://dx.doi.org/10.1007/s00467-006-0113-7

[3] J. Rodrígu-Soriano, "Bartter and Related Syndromes; the Puzzle Is Almost Solved," Pediatric Nephrology, Vol. 12, No. 4, 1998, pp. 315-327. http://dx.doi.org/10.1007/s004670050461

[4] I. Kurtz, "Molecular Pathogenesis of Bartter's and Gitelman's Syndromes," Kidney International, Vol. 54, No. 4, 1998, pp. 1396-1410. http://dx.doi.org/10.1046/j.1523-1755.1998.00124.x

[5] K. Sampathkumar, U. Muralidharan, A. Kannan, M. Ramakrishnan and R. Ajeshkumar, "Childhood Bartter's Syndrome: An Indian Case Series," Indian Journal of Nephrology, Vol. 20, No. 4, 2010, pp. 207-210. http://dx.doi.org/10.4103/0971-4065.73455

[6] P. Samayam, B. R. Chander and V. R. S. Reddy, "An Unusual Cause of Failure to Thrive in a Child," The National Medical Journal of India, Vol. 24, No. 2, 2011, pp. 86-87.

[7] P. S. Kumar, M. Deendayalan, L. Janakiraman and M. Vijakumar, "Neonatal Batter Syndrome," Indian Pediatrics, Vol. 43, No. 8, 2006, pp. 735-737. 